\title{
Targeting Regulatory T Cells to Treat Patients With Systemic Lupus Erythematosus
}

\author{
Masayuki Mizui ${ }^{*}$ and George C. Tsokos ${ }^{2 *}$ \\ ${ }^{1}$ Department of Nephrology, Osaka University Graduate School of Medicine, Suita, Osaka, Japan, ${ }^{2}$ Division of \\ Rheumatology, Department of Medicine, Beth Israel Deaconess Medical Center and Harvard Medical School, Boston, MA, \\ United States
}

Regulatory T cells (Tregs) are central in integration and maintenance of immune homeostasis. Since breakdown of self-tolerance is a major culprit in the pathogenesis of systemic lupus erythematosus (SLE), restoration of the immune tolerance through the manipulation of Tregs can be exploited to treat patients with SLE. New information has revealed that Tregs besides their role in suppressing the immune response are important in tissue protection and regeneration. Expansion of Tregs with low-dose IL-2 represents

OPEN ACCESS

Edited by:

Pierre Miossec,

Claude Bernard University

Lyon 1, France

Reviewed by:

Qianjin Lu,

Central South University, China Jian Zhang,

University of lowa,

United States

*Correspondence:

Masayuki Mizui

mmizui@kid.med.osaka-u.ac.jp;

George C. Tsokos

gtsokos@bidmc.harvard.edu

Specialty section:

This article was submitted to Inflammation,

a section of the journal

Frontiers in Immunology

Received: 28 February 2018

Accepted: 29 March 2018

Published: 17 April 2018

Citation:

Mizui M and Tsokos GC (2018) Targeting Regulatory T Cells to Treat Patients With Systemic Lupus Erythematosus. Front. Immunol. 9:786. doi: 10.3389/fimmu.2018.00786 an approach to control the autoimmune response. Moreover, control of Treg metabolism can be exploited to restore or improve their function. Here, we summarize the function and diversity of Tregs and recent strategies to improve their function in patients with SLE.

Keywords: systemic lupus erythematosus, regulatory T cells, tissue Treg, low-dose IL-2 treatment, immunometabolism

\section{INTRODUCTION}

Breakdown of self-tolerance is critical in the development of systemic lupus erythematosus (SLE) (1). Innate and adaptive immune responses against self-antigen induce the production of autoantibodies and the deposition of immune-complexes in tissues leads to the activation of complement, accumulation of neutrophils and monocytes, and self-reactive lymphocytes (2). The variety of clinical manifestations may reflect the multiple and heterogeneous pathways that account for the expression of disease (3). Chronic inflammation caused by the immune response against self-antigens leads to the development of irreversible damage in tissues including the kidney. Efforts to resolve or contain the inflammatory response include curtailing autoantibody production and the levels of type I interferon and various chemoattractants $(4,5)$. Belimumab, the soluble B-lymphocyte stimulator (BAFF) blocking antibody, which has been approved by FDA to treat patients with SLE has marginal clinical efficacy and only in patients with moderate disease. However, post hoc analysis and long-term follow-up studies have revealed that belimumab does not induce a rapid clinical benefit and the clinical efficacy seems to be limited (6). Recent advances in our understanding of regulatory $\mathrm{T}$ cell (Treg) physiology and metabolism have fueled new therapeutic strategies which involve the improvement of Treg function for the treatment of SLE and other autoimmune diseases as well as transplant rejection and cancer $(7,8)$. Low-dose IL-2 supplementation was first shown to expand Tregs and improve clinical manifestations in patients with chronic graft-versus-host disease (cGVHD) and hepatitis $\mathrm{C}$ virus-associated vasculitis $(9,10)$. Low-dose IL-2 therapy has been claimed in case reports and non-controlled studies to improve Treg numbers and clinical manifestations in patients with $\operatorname{SLE}(11,12)$. Ongoing clinical trials (NCT03312335: Charact-IL-2, NCT 01988506: TRANSREG) will test the therapeutic value of low-dose IL-2 in patients with SLE. Therefore, a better understanding of the molecular 
events which account for the poor function of Tregs in patients with SLE along with their poor response to IL-2 is needed to optimize therapeutic approaches. Further, it should be clarified how Tregs may contribute to containing tissue inflammation or repair organ damage. Tregs can modulate the function of the immune system as well as the function of non-lymphoid organs through the acquisition of tissue-defined gene expression.

\section{PLEIOTROPIC EFFECTS OF Tregs}

\section{Treg Subsets and Tissue Tregs}

Self-tolerance is accomplished with the deletion of self-reactive lymphocytes during development. However, self-reactive T cells escape negative selection in the thymus and persist in the periphery (13), where Tregs are important gatekeepers in preventing aberrant activation of self-reactive lymphocytes. Tregs develop in the thymus (tTreg) through strong $\mathrm{T}$ cell receptor (TCR) signaling just below the threshold for negative selection. Therefore, Tregs recognize self-antigens for their differentiation. Tregs are also induced from naïve $\mathrm{CD} 4^{+} \mathrm{T}$ cells (pTreg) (14). In the human, peripheral blood Tregs may be present in resting $\left(\right.$ Foxp $\left.^{+} \mathrm{CD} 45 \mathrm{RA}^{+} \mathrm{CD} 25^{+} \mathrm{CD} 127^{-}\right)$or activated/memory (Foxp $3^{++} \mathrm{CD} 45 \mathrm{RA}^{-} \mathrm{CD} 25^{++} \mathrm{CD} 127^{-}$) phenotype (Table 1) (15). A subset of memory Tregs is known as T helper-like Tregs which can be further classified, depending on the kind of environmental stimuli, as T helper-like Tregs type1 (TH1), TH2, TH17-like, and T-follicular regular populations which co-express T-bet, GATA3/ IRF4, ROR $\gamma$ t, and Bcl6, respectively $(16,17)$. These T helper-like memory Tregs share chemokine receptors with individual $\mathrm{T}$ helper cells and are thought to be distributed into the appropriate site of each class of the immune response (13). Besides the conventional Tregs, $\mathrm{CD}^{+}{ }^{+}$Foxp $3^{-}$type 1 T regulatory $(\operatorname{Tr} 1)$ cells expressing IL-10 were recently identified and shown to display strong immunosuppressive activity and to be involved in the maintenance of tolerance (18-20).

In tissues, Tregs are more abundant, percentage-wise, than in the peripheral blood and most of tissue-resident Tregs have an activated/memory phenotype (21). Moreover, gene expression patterns in tissue-resident Tregs depend distinctly on the hosting tissue. For example, an intestinal pTreg subset expresses ROR $\gamma \mathrm{t}$ and can produce IL-17 (22) and visceral adipose tissue (VAT) Tregs express PPAR $\gamma$ to regulate insulin sensitivity $(23,24)$. VAT Tregs also highly express IL-33 receptor (ST2), a receptor for alarmin that induces $\mathrm{T}_{\mathrm{H}} 2$ responses, which is required for Treg accumulation into VAT (25). Tregs seem to be formed in the thymus by the time of birth but they diverge dependent on the tissue environment. Perinatally generated tTregs that are Airedependent translocate into tissues and persist to maintain selftolerance (26). In addition, some strains of gut microbiota can induce Tregs in intestine (27). Therefore, colonic Tregs originate from both $\mathrm{t}$ Treg and $\mathrm{pTreg}$ but VAT and muscle Tregs are reported to be of thymic origin (tTreg) (28). The biology and characteristics of human tissue-resident Tregs have been reviewed (29) and are summarized in Table 1 (30-34).

\section{Immunosuppressive Aspects of Tregs}

The suppressive action of Tregs on effector T cells (Teffs) is well established. First, Tregs inhibit Teff expansion by consuming local IL-2 because they express higher levels of CD25 (35). Second, Tregs inhibit Teffs in a contact-dependent manner. Tregs downregulate the expression of costimulatory ligands CD80/86 on antigen-presenting cells through trans-endocytosis. This is accomplished by CTLA4 which is expressed on Tregs and binds to CD80/86 with higher affinity than CD28 (36). Furthermore, Tregs can deprive energy factors from Teff cells. CTLA4-mediated signals induce indoleamine 2,3-dioxygenase in antigen-presenting cells resulting in the starvation of Teff cells $(37,38)$. A subset of Treg expresses an ectonucleotidase CD39 which catalyzes the degradation of proinflammatory molecule adenosine triphosphate (ATP) into adenosine diphosphate (ADP) and adenosine monophosphate (AMP) and dampens Teff activation and proliferation (39). In the resting state, Tregs localize in clusters of IL-2-producing $\mathrm{T}$ cells that are activated by self-antigen within secondary lymphoid tissues (35). Many other different mechanisms of suppression have been documented and are summarized in Table $2(38,40)$. Recently, Tregs were shown to suppress autophagy in antigen-presenting cells and thus limit the production of autoantigens (41).

\section{Tregs in Wound Repair and Tissue Regeneration}

Neutrophils and myeloid mononuclear cells such as monocytes infiltrate injured tissues in early phases. Monocytes differentiate into M1-type macrophages which are involved in the clearance of apoptotic and necrotic cells and debris and subsequently to M2-type macrophages which become involved in matrix

TABLE 1 | Genes and phenotypes of regulatory T cells detected in humans.

\begin{tabular}{|c|c|c|c|c|c|c|c|c|c|c|}
\hline Tissue & Phenotype & Foxp3 & CD45RA & CD25 & CTLA4 & GITR & ICOS & CD127 & Others genes & References \\
\hline \multirow[t]{3}{*}{ Blood } & Resting/naive & + & + & + & - & - & - & - & & (15) \\
\hline & Activated/memory & ++ & - & ++ & + & + & + & - & T-bet, GATA-3, ROR $\gamma$ t, Bcl-6 & $(13,16,17)$ \\
\hline & Type 1 T regulatory & - & - & - & n.d. & n.d. & + & - & IL-10, CD49b, LAG3, AhR & $(18-20)$ \\
\hline Skin & Memory & + & - & ++ & + & + & + & - & $\mathrm{IL}-17$ & $(46)$ \\
\hline Lung & Activated & + & - & + & + & - & + & - & & (30) \\
\hline Colon & Effector & ++ & - & ++ & + & + & n.d. & - & IL-17, ROR $\gamma t$, CD49d, CD103 & $(22,31)$ \\
\hline Visceral adipose tissue & Activated & + & $-/+$ & + & n.d. & n.d. & n.d. & - & ST2, OX40 & $(25,32,34)$ \\
\hline Joint & Activated & + & - & ++ & n.d. & n.d. & n.d. & - & IL-17, CD161 & (33) \\
\hline
\end{tabular}

n.d., not determined. 
TABLE 2 | Modes of action of Tregs.

\begin{tabular}{|c|c|c|}
\hline Target & Modes of actions & Reference \\
\hline \multirow[t]{4}{*}{ Effector T cells } & $\begin{array}{l}\text { IL-2 consumption to inhibit clonal } \\
\text { expansion }\end{array}$ & \\
\hline & $\begin{array}{l}\text { Suppressive cytokine secretion } \\
\text { (TGF } \beta, \text { IL-10, IL-35) }\end{array}$ & $(38)$ \\
\hline & $\begin{array}{l}\text { Hydrolysis of adenosine phosphates } \\
\text { via CD39, CD73 }\end{array}$ & $(39)$ \\
\hline & $\begin{array}{l}\text { Direct cell killing via perforin/ } \\
\text { granzyme }\end{array}$ & $(40)$ \\
\hline \multirow[t]{3}{*}{$\begin{array}{l}\text { Dendritic cells/antigen- } \\
\text { presenting cells }\end{array}$} & $\begin{array}{l}\text { Blocking CD80/86 through } \\
\text { CTLA4 }\end{array}$ & $(36)$ \\
\hline & $\begin{array}{l}\text { Inhibition of autophagy through } \\
\text { CTLA4 }\end{array}$ & $(41)$ \\
\hline & Indoleamine 2,3-dioxygenase induction & $(37)$ \\
\hline Hair follicle stem cells & $\begin{array}{l}\text { Promoting proliferation } \\
\text { and differentiation }\end{array}$ & $(48)$ \\
\hline Muscle progenitor cells & $\begin{array}{l}\text { Amphiregulin-mediated } \\
\text { differentiation }\end{array}$ & $(43)$ \\
\hline Adipocytes & $\begin{array}{l}\text { Maintain insulin tolerance } \\
\text { through IL-10 }\end{array}$ & (23) \\
\hline
\end{tabular}

remodeling and promotion of angiogenesis and tissue regeneration (42). Lymphocytes, including $\mathrm{CD} 4^{+}$and $\mathrm{CD} 8^{+} \mathrm{T}$ cells, are also recruited to the sites of inflammation and have been thought to promote tissue injury. Recent reports though have demonstrated that $\mathrm{CD}^{+}{ }^{+}$Foxp $3^{+}$Tregs accumulate in the skeletal muscle after injury on time to switch from proinflammatory to the proregenerative (43). The Treg population persists at high numbers even 1 month after the injury. Notably, these Tregs express high levels of amphiregulin (Areg), an epithelial growth factor (EGF) family protein, and promote muscle regeneration through the EGF receptor (EGFR) signaling axis (43). Tregs expressing Areg can protect lungs from infection-induced damage (44). In addition, Tregs also express EGFR and the Areg-EGFR axis is critical for the local Treg function. Areg is produced not only by Tregs but by Th2 cells and other myeloid cells including mast cells and control the immune response by regulating Treg cell function (45). Involvement of Areg-EGFR signals in Treg-mediated tissue regeneration is also observed in skin injury by promoting wound healing $(46,47)$. Furthermore, the same group recently demonstrated that skin Tregs preferentially reside close to hair follicle stem cells (HFSCs) and help HFSC-mediated hair regeneration (48). More recently, Tregs were demonstrated to promote directly myelin regeneration in the central nervous system indecently of immunomodulation (49).

\section{IL-2, Tregs, AND SLE}

\section{IL-2 Deficiency and Impaired Treg Function in SLE}

While IL-2 is critical for the differentiation and function of Tregs, it is a well-known fact that IL-2 production by conventional $\mathrm{T}$ cells (Tconv) is impaired in SLE (50). IL-2 gene is silenced through transcriptional regulator, cyclic AMP response element modulator alpha (CREM $\alpha$ ), which is overexpressed by SLE Tconv cells. Repression of IL-2 also caused by enhancement of calcium/ calmodulin-dependent kinase IV (CaMK4) (51) and decrease of serine/arginine-rich splicing factor $1(52,53)$. The absence of IL-2 probably favors differentiation and expansion of IFN $\gamma$-producing $\mathrm{T}_{\mathrm{H}} 1$ cells and IL-17-producing $\mathrm{T}_{\mathrm{H}} 17$ cells, accumulating in organs such as the skin and the kidney $(54,55)$. Regulatory T cell numbers decrease in lupus-prone mice as they age and the disease progresses (56). In humans, several studies have analyzed the frequency of Tregs in SLE and reported conflicted results (57). The reported discrepancies may be due to the applied gating strategies in flow cytometry. Some studies gated Tregs based only the expression of Foxp $3^{+} \mathrm{CD} 25^{+}$cells a population which contains non-Treg activated $\mathrm{T}$ cells. Recent studies using less ambiguous gating strategies reported that $\mathrm{CD} 45 \mathrm{RA}^{+} \mathrm{CD} 25^{+}$naïve Treg and CD45RA-CD25 ${ }^{++}$activated Tregs in SLE patients are comparable to those in healthy individuals, although the frequency of CD45RA-CD25 ${ }^{+}$activated $T$ cells showed linear relationship with SLEDAI (58). In addition, Foxp $3^{+} \mathrm{T}$ cells in the kidney and skin are comparable to those seen in tissues obtained from several control diseases. Considering that IL-2 production by $\mathrm{T}$ cells from SLE patients is impaired, it appears that this deficiency does not influence the numbers of Tregs in SLE. However, recent studies described that CD25 expression levels on the surface of Tregs were decreased in SLE patients (59). The reduction of CD25 expression in Tregs from patients with SLE correlated with the production of IL- 2 by memory $\mathrm{T}$ cells indicating that deficiency of IL-2 in SLE patients reflects CD25 reduction in Tregs. Because IL-2 receptor-dependent activation of transcription factor STAT5 is essential for the suppressive function of Tregs, decreased expression of CD25 may affect the function of Tregs in SLE patients.

\section{IL-2 Therapy in Lupus-Prone Mice}

The first report of IL-2 treatment for lupus-prone mice presented in 1990 prior to the discovery of Tregs (60). An IL-2-encoding vaccinia virus was used to deliver IL-2 in vivo in MRLlpr mice. Treated mice survived longer and had reduced lymphadenopathy and kidney pathology. As TCR $\alpha \beta^{+} \mathrm{CD} 4{ }^{-C D} 8^{-}$(double-negative, DN) $\mathrm{T}$ cells are the most likely culprit of lymphoadenopathy in MRLlpr mice, these DN T cells were significantly decreased after treatment with IL-2. Several methods for delivering IL-2 have been tried and confirmed these findings (61-63). Although DN $\mathrm{T}$ cells are also expanded in patients with SLE, their origin of is still unclear. DN T cells from lupus-prone mice and patients with SLE produce IL-17 $(63,64)$, indicating involvement of DN $\mathrm{T}$ cells in the pathogenesis of SLE. By IL-2 supplementation, Treg number is increased substantially in lymphoid and peripheral organs in NZB/NZW F1 mice and MRL/lpr mice and DN Tcells are significantly decreased in MRL/lpr mice $(56,63)$. However, Treg-specific expansion following the administration of IL-2/ anti-IL-2 antibody complexes did not lead to the reduction of DN T cells (63), suggesting that an effect of IL-2 on non-Treg population might contribute to the inhibition of DN T cell expansion.

\section{IL-2 Therapy for Patients With SLE}

Deficiency of IL-2 production in patients with SLE might contribute to detrimental perturbation in immune systems. Therefore, it is conceivable that low-dose IL-2 treatment can restore 
these pathogenic processes (65). Humrich and colleagues first reported a patient with SLE who achieved clinical improvement following treatment with low-dose IL-2. Specifically, 1.5 to $3 \times 10^{6}$ IU IL-2 (aldesleukin) was injected subcutaneously on five consecutive days for four cycles with 9-16 days of separation. Skin eruption, myositis and arthritis were improved within 10 days and serum anti-dsDNA antibody titer was decreased after for cycles of treatment. CD $4{ }^{+} \mathrm{CD} 25^{+} \mathrm{Foxp} 3^{+} \mathrm{CD} 127^{\text {lo }}$ Tregs were upregulated temporarily at around $40 \%$ among $\mathrm{CD} 4^{+} \mathrm{T}$ cells (11). Subsequently, they conducted a combined phase I/IIa clinical trial to address the safety, tolerability, efficacy, and immune response of low-dose IL-2 therapy in patients with active and refractory SLE (PRO-IMMUN, EudraCT-number: 2013001599-40, Germany) (66). In this study, they demonstrated that Tregs from SLE patients showed decreased number of CD25 high population and that IL-2 production was deficient in SLE CD4 ${ }^{+}$ $\mathrm{T}$ cells. After five patients were treated with daily subcutaneous injection of IL- 2 at $1.5 \times 10^{6} \mathrm{IU}$ for 5 days, they confirmed that low-dose IL-2 therapy induced substantial increases of the numbers of Tregs without major side effects. As the primary endpoint (immune response rate) has been completed, phase II trial is now ongoing. The latest clinical trial of low-dose IL-2 in 38 SLE patients in China (NCT02084238) demonstrated that IL-2 treatment significantly decreased SLEDAI after 12 weeks (12). Subcutaneous $1 \times 10^{6}$ IU of IL-2 was administered alternateday for seven times at three cycles. More than $80 \%$ of patients achieved composite endpoint of SLE response index with 4-point drop in SLEDAI (SRI(4)), with increased Tregs, decreased $\mathrm{T}_{\mathrm{H}} 17$, Tfh, and DN T cells. Unfortunately, the study was not controlled and various observations including the rapid disappearance of DNA antibodies remain unexplained. Another clinical study involving the induction of Tregs by low-dose IL-2 in SLE and other autoimmune and inflammatory diseases (Charact-IL-2 and TRANSREG) is now in progress (67). Since all studies are non-controlled ones, controlled prospective study is necessary. Taken together, low-dose IL-2 treatment in SLE patients could alleviate clinical severity by altering the balance of T-cell subsets.

\section{Efficacy and Safety of Low-Dose IL-2 Therapy}

Further analysis using mass cytometry of low-dose IL-2 treatment in cGVHD patients revealed that $\mathrm{CD} 4^{+} \mathrm{CD} 25^{+} \mathrm{Foxp}^{+} \mathrm{Helios}^{+}$ Tregs and $\mathrm{CD} 56^{\text {bright }} \mathrm{CD} 16^{-} \mathrm{NK}$ cells were selectively expanded (68). Helios ${ }^{+}$Tregs were shown to be fully demethylated at the Treg-specific demethylated region and was recognized as a subset with enhanced suppressive potential (69). Ki67 expression was increased 1 week after starting IL- 2 but declined to baseline after 12 weeks. It is notable that even 48 weeks after daily treatment with low-dose IL-2, phosphorylation of STAT5 and increased expression of Foxp3, CTLA-4, CD25, and Bcl-2 were sustained (68). A recent study reported that inflammation-experienced memory Tregs exert enhanced suppressive function which was lost over time to obviate general immunosuppression (70).

Long-term treatment with low-dose IL-2 has been tested in mice. Recombinant adeno-associated vector (rAAV) encoding IL-2 was injected intraperitoneally at various viral titers. This approach enabled sustained higher IL-2 concentrations for more than 20 weeks compared to controls and substantially prevented diabetes in NOD mice (71). Although mice injected with high viral titers $\left(10^{12} \mathrm{rAAV}\right.$ IL-2) died within 2 weeks, mice injected with lower titer $\left(10^{9}-10^{11}\right.$ rAAV-IL-2) lived normal life spans with unaffected vaccine-mediated antibody responses, infection-induced immune responses, and notably, not-enhanced tumor growth (71). Interestingly, low-dose recombinant IL-2 administration could protect mice from food allergy and the immune tolerance was sustained for more than 7 months after the last dose of IL-2 (72). These results indicate that Tregs can maintain their specific inhibitory function during long-term exposure to IL-2 and long thereafter.

\section{Manipulation of IL-2}

Although low-dose IL-2 can substantially expand Tregs, frequent injection is required for the induction of significant increase because of its short half-life in human serum (5-7 min). To overcome this disadvantage, modified IL-2 such as polyethylene glycol-modified IL-2 (PEG-IL-2), which prolongs the halflife of IL-2, has been constructed. PEG-IL-2 has been developed in the 1990s and undergone phase I/II clinical trials in cancer patients (73) and was recently revisited and tried in mice with asthma (74). Bell et al. recently developed monovalent or bivalent IL-2-fused with non-FcR binding IgG1 molecules which had a prolonged half-life in vivo and caused prolonged activation and proliferation of Tregs after a single ultra-low dose (75). IL-2/ anti-IL-2 complexes can also prolong the half-life of IL-2. In mice, IL-2/anti-IL-2 complexes have been well established: IL-2/ JES6-1A12 specifically binds to CD25 and IL-2/S4B6 selectively binds to CD122. IL-2/JES6-1A12 and IL-2/S4B6 induce specific expansion of Tregs and cytotoxic lymphocytes, respectively. IL-2/ JES6-1A12 administration was shown to expand efficiently both peripheral and tissue Tregs $(43,76)$. When human IL-2/antiIL-2 complexes are fully developed, they will be useful for the specific expansion of target cells and will probably require less frequent injections (77). Biologic nanoparticles have attracted attention over the years for targeted therapy. For example, nanoscale liposomal polymeric gels (nanolipogels) are biologically compatible and slowly biodegradable agents. Fahmy and colleagues recently developed nanolipogels encapsulated recombinant IL- 2 and TGF $\beta$, and anti-CD4-labeled nanolipogels with IL- 2 and TGF $\beta$ successfully expand Tregs in vitro and in vivo (78). Use of IL-2-nanoparticles tagged with an antibody recognizing specific tissues will result in bore specific delivery and lower toxicity.

\section{TARGETING METABOLISM TO INCREASE Treg STABILITY}

\section{Mechanistic Target of Rapamycin (mTOR)}

Dynamic changes of cellular metabolism are necessary for efficient immune cell activation, growth, proliferation, and differentiation. In the quiescent state, $\mathrm{T}$ cells use mitochondrial tricarboxylic acid cycle to generate ATP and sustain homeostasis. When stimulated, cell metabolism shifts to anabolic pathways 
to produce building blocks needed to promote and sustain cell proliferation. Therefore, glycolytic metabolism is induced in activated T cells. The hosphatidylinositol-3-kinase (PI3K)-AktmTOR pathway plays a critical role in the regulation of glycolysis. Generally, resting Tregs utilize a distinct metabolic program based on mitochondrial oxidation of lipids ( $\beta$-oxidation). When Tregs proliferate, glycolysis is also observed but their suppressive function is reduced. Conversely, Foxp3 inhibits the PI3KAkt-mTOR pathway and glycolysis (79). mTOR consists of two multiprotein complexes (mTORC1 and mTORC2) and acts as a critical regulator of cell growth, metabolism, differentiation and survival. In mice with Treg-specific depletion of the regulatoryassociated protein of mTOR, a component of mTORC1, Tregs lose their suppressive function resulting into severe autoimmunity (80). Inhibition of mTORC2 by mTORC1 has been shown to be important for Treg function and generation. On the other hand, mTORC1 inhibits de novo Treg differentiation and proliferation (81). Furthermore, uncontrolled activation of mTORC1 leads to the development of autoimmunity with deficiency of suppressive function of Tregs (82). Several studies with mice deficient in the mTOR regulatory systems showed functional impairment of Tregs that leads to systemic autoimmunity (82-85). Human Tregs have been reported to be expanded efficiently in the presence of the mTORC1 inhibitor rapamycin (86). In SLE, activated mTOR in T cells accounts for several abnormalities including the downregulation of $\mathrm{CD} 3 \zeta$, the expansion of $\mathrm{T}_{\mathrm{H}} 17$ and $\mathrm{CD}^{+} \mathrm{CD}^{-}{ }^{-} \mathrm{CD} 8^{-} \mathrm{DN} \mathrm{T}$ cells and the contraction of Tregs $(87,88)$. Administration of rapamycin has been reported to improve clinical outcomes in lupus-prone mice (89) and patients with SLE (90). Moreover, rapamycin can block the production of antiphospholipid antibody in lupus-prone mice (91) and enhance renal allograft survival of antiphospholipid syndrome patients (92). Therefore, rapamycin is a promising candidate for the treatment of patients with SLE because it normalizes various $\mathrm{T}$ cell functions including that of Tregs. Interestingly, inhibition of both mitochondrial electron transport by metformin and glucose metabolism by 2-deoxy-D-glucose (2DG) ameliorated disease in lupus-prone mice and cGVHD (93). Metformin can also inhibit mTORC1 by activating AMPK. Activated T cells, Tfh, and germinal center B cell and anti-dsDNA antibody titer were decreased, indicating that metabolic control can prevent aberrant activation of immune cells in autoimmunity (93).

\section{Calcium/Calmodulin-Dependent Kinase IV (CaMK4)}

CaMK is a serine/threonine kinase family protein which becomes activated when intracellular calcium binds to calmodulin to generate the calcium/calmodulin complex. CaMK4 translocates

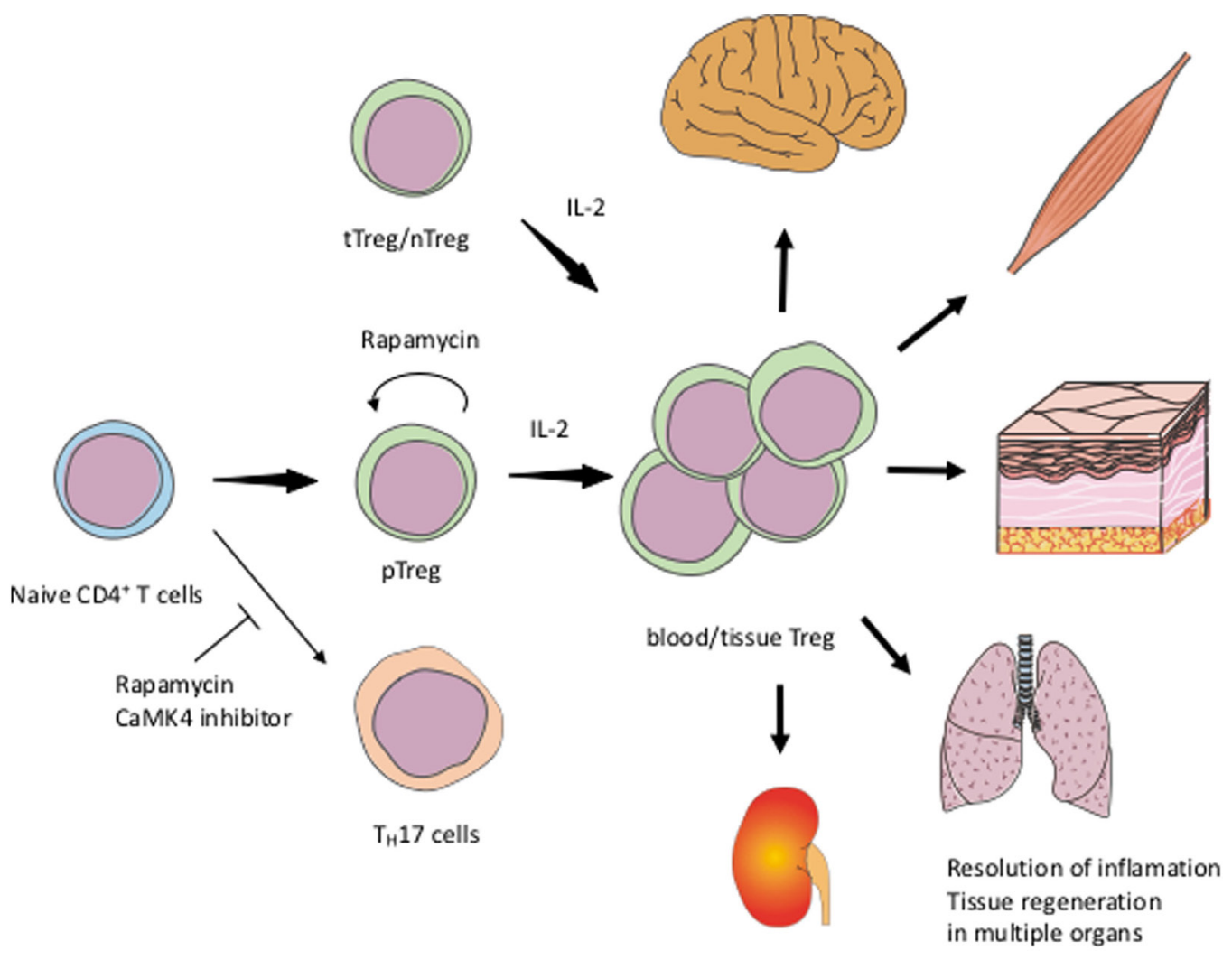

FIGURE 1 | Schematic view of exploiting Tregs for the treatment of SLEIL-2 expands both tTreg/nTreg and pTreg including tissue Treg. Rapamycin and CaMK4 inhibitor facilitate the differentiation of Treg and inhibit $T_{H} 17$. Rapamycin can also stabilize the Treg function. tTreg, thymic regulatory T-cells; nTreg, naïve Treg; pTreg, peripheral Treg; $T_{H} 17, \mathrm{IL}-17$-producing helper T-cells. 
in the nucleus and regulates the activation of several transcription factors including CREB and CREM (94). CaMK4 expression of SLE T cells is upregulated and CaMK4-deficient lupus mice show amelioration of autoimmunity with decreased $\mathrm{T}_{\mathrm{H}} 17$ and increased Treg cell numbers. Therefore, CaMK4 is involved in the pathogenesis of SLE by altering the balance between $T_{H} 17$ and Treg cells. Both $\mathrm{T}_{\mathrm{H}} 17$ and iTreg cells need TGF $\beta$ for their development. T cells expressing both Foxp3 and ROR $\gamma \mathrm{t}$ are generated intermediately and can differentiate to $\mathrm{T}_{\mathrm{H}} 17$ or iTreg dependent on the milieu. Therefore, $\mathrm{T}_{\mathrm{H}} 17$ and iTreg cells display plasticity which allows them to exchange phenotype. We recently reported that CaMK4 regulates $\mathrm{T}_{\mathrm{H}} 17$ cell differentiation by activating AktmTOR pathway as well as by enhancing CREM $\alpha$-mediated IL-17 transcription (51). CaMK4 is preferentially expressed by $\mathrm{T}_{\mathrm{H}} 17$ cells and its deficiency mitigated the differentiation of naïve $\mathrm{CD} 4^{+}$ T cells into $\mathrm{T}_{\mathrm{H}} 17$ cells. Because the mTOR-TORC1 pathway is essential for $\mathrm{T}_{\mathrm{H}} 17$ differentiation, CaMK4-Akt-mTOR axis might be critical for effective $\mathrm{T}_{\mathrm{H}} 17$ development. Moreover, administration of the CaMK4 inhibitor KN93 sufficiently expanded Tregs in vivo and alleviated disease in lupus-prone mice. Lastly, Otomo et al showed that anti-CD4-tagged nanoparticles loaded with KN93 selectively delivered the drug to $\mathrm{CD}^{+}$lymphocytes and mitigated disease in lupus-prone mice and in mice induced to develop experimental autoimmune encephalomyelitis (95).

\section{Treg INFUSION THERAPY}

Several studies using animal models have demonstrated that adaptive transfer of natural or ex vivo-expanded Tregs can inhibit GVHD $(96,97)$ and solid organ transplant rejection (98). Treg infusion for human GVHD has been reported to be effective and currently a number of clinical trials involving the infusion of Tregs in patients receiving hematopoietic stem cell, kidney, and liver transplants are in progress (99). Since the number of Tregs which can be isolated from the peripheral blood or umbilical cord blood is limited, various strategies to expand Tregs in vitro have been considered including anti-CD3/CD28-coated beads in the presence of IL- 2 and/or TGF- $\beta$ and in the presence or absence of rapamycin (NCT02129881, NCT01624077). A recent study confirmed besides the efficacy, the safety, and feasibility of the injection of isolated or ex vivo-expanded Tregs in patients receiving transplant organs (100). Treg cell therapy is also ongoing in patients with type 1 diabetes (T1D) based on the evidence that deficiency of Tregs is important in the pathogenesis of the disease. A phase I trial (NCT01210664) designed to assess safety of adoptive Treg immunotherapy in patients with T1D has been

\section{REFERENCES}

1. Tsokos GC. Systemic lupus erythematosus. N Engl J Med (2011) 365:2110-21. doi:10.1056/NEJMra1100359

2. Tsokos GC, Lo MS, Costa Reis P, Sullivan KE. New insights into the immunopathogenesis of systemic lupus erythematosus. Nat Rev Rheumatol (2016) 12:716-30. doi:10.1038/nrrheum.2016.186

3. Moulton VR, Suarez-Fueyo A, Meidan E, Li H, Mizui M, Tsokos GC. Pathogenesis of human systemic lupus erythematosus: a cellular perspective. Trends Mol Med (2017) 23:615-35. doi:10.1016/j.molmed.2017. 05.006 completed. Specifically, T1D patients received ex vivo-expanded autologous $\mathrm{CD} 4^{+} \mathrm{CD} 127^{\text {low/ }} \mathrm{CD} 25^{+}$polyclonal Tregs $\left(0.05 \times 10^{8}\right.$ to $26 \times 10^{8}$ cells) using anti-CD3/CD28 beads plus IL-2. Twenty-five percent of transferred Tregs were detected even after one year without any adverse effect (101). A study involving the infusion of expanded autologous Tregs in a similar manner for the treatment of SLE has now been launched (NCT02428309). Since adaptive transfer of Treg in the setting of lupus-prone mice was reported effective in the suppression of glomerulonephritis and prolonging survival $(102,103)$, clinical efficacy is also expected from the trial in patients with SLE.

\section{CONCLUDING REMARKS AND FUTURE PERSPECTIVES}

Sustained production of autoantibody and intermittent release of self-antigen can induce chronic activation of innate and adaptive immune responses in SLE. Chronic inflammatory conditions induce aberration of the immune system homeostasis. Further studies are necessary to elucidate the detailed mechanisms by which Tregs suppress autoimmune-associated tissue inflammation and regeneration.

Low-dose IL-2 for the treatment of patients with SLE appears to be a promising, selective therapeutic strategy to expand Tregs numerically and functionally. Formulations of IL-2 to expand its half-life in the blood and to decrease the number of required injections are needed. Rapamycin and CaMK4 inhibitors would also be candidate drugs to enhance Treg function (Figure 1). IL-2/Sirolimus/Tacrolimus combination therapy was tried in patients undergoing hematopoietic stem cell transplantation with promising results (104). In mice, combination therapy of IL-2 and rapamycin effectively expanded Tregs and prevented acute rejection of skin grafts (105). Clinical trials of Treg-targeted treatments are currently in progress and it is expected to demonstrate that expansion or supplementation of Tregs can be added to the treatment choices physicians have in their disposal to treat patients with SLE.

\section{AUTHOR CONTRIBUTIONS}

MM and GT wrote and edited the review.

\section{FUNDING}

This work was supported by JSPS KAKENHI Grant Number JP17K10001.

4. Lo MS, Tsokos GC. Recent developments in systemic lupus erythematosus pathogenesis and applications for therapy. Curr Opin Rheumatol (2017) 30(2):222-8. doi:10.1097/BOR.0000000000000474

5. Kyttaris VC. Novel treatments in lupus. Curr Rheumatol Rep (2017) 19:10. doi:10.1007/s11926-017-0638-8

6. Guerreiro Castro S, Isenberg DA. Belimumab in systemic lupus erythematosus (SLE): evidence-to-date and clinical usefulness. Ther Adv Musculoskelet Dis (2017) 9:75-85. doi:10.1177/1759720X17690474

7. von Boehmer H, Daniel C. Therapeutic opportunities for manipulating $\mathrm{T}(\mathrm{Reg})$ cells in autoimmunity and cancer. Nat Rev Drug Discov (2013) 12:51-63. doi:10.1038/nrd3683 
8. Galgani M, De Rosa V, La Cava A, Matarese G. Role of metabolism in the immunobiology of regulatory T cells. J Immunol (2016) 197:2567-75. doi:10.4049/jimmunol.1600242

9. Koreth J, Matsuoka K, Kim HT, McDonough SM, Bindra B, Alyea EP III, et al. Interleukin-2 and regulatory T cells in graft-versus-host disease. $N$ Engl J Med (2011) 365:2055-66. doi:10.1056/NEJMoa1108188

10. Saadoun D, Rosenzwajg M, Joly F, Six A, Carrat F, Thibault V, et al. Regulatory T-cell responses to low-dose interleukin-2 in HCV-induced vasculitis. $N$ Engl J Med (2011) 365:2067-77. doi:10.1056/NEJMoa1105143

11. Humrich JY, von Spee-Mayer C, Siegert E, Alexander T, Hiepe F, Radbruch A, et al. Rapid induction of clinical remission by low-dose interleukin-2 in a patient with refractory SLE. Ann Rheum Dis (2015) 74:791-2. doi:10.1136/ annrheumdis-2014-206506

12. He J, Zhang X, Wei Y, Sun X, Chen Y, Deng J, et al. Low-dose interleukin-2 treatment selectively modulates CD4(+) T cell subsets in patients with systemic lupus erythematosus. Nat Med (2016) 22:991-3. doi:10.1038/nm.4148

13. Josefowicz SZ, Lu LF, Rudensky AY. Regulatory T cells: mechanisms of differentiation and function. Annu Rev Immunol (2012) 30:531-64. doi:10.1146/ annurev.immunol.25.022106.141623

14. Shevach EM, Thornton AM. tTregs, pTregs, and iTregs: similarities and differences. Immunol Rev (2014) 259:88-102. doi:10.1111/imr.12160

15. Miyara M, Yoshioka Y, Kitoh A, Shima T, Wing K, Niwa A, et al. Functional delineation and differentiation dynamics of human CD4+ T cells expressing the FoxP3 transcription factor. Immunity (2009) 30:899-911. doi:10.1016/j. immuni.2009.03.019

16. Duhen T, Duhen R, Lanzavecchia A, Sallusto F, Campbell DJ. Functionally distinct subsets of human FOXP3+ Treg cells that phenotypically mirror effector Th cells. Blood (2012) 119:4430-40. doi:10.1182/blood-2011-11-392324

17. Halim L, Romano M, McGregor R, Correa I, Pavlidis P, Grageda N, et al. An atlas of human regulatory $\mathrm{T}$ helper-like cells reveals features of Th2-like Tregs that support a tumorigenic environment. Cell Rep (2017) 20:757-70. doi:10.1016/j.celrep.2017.06.079

18. Gagliani N, Magnani CF, Huber S, Gianolini ME, Pala M, Licona-Limon P, et al. Coexpression of CD49b and LAG-3 identifies human and mouse T regulatory type 1 cells. Nat Med (2013) 19:739-46. doi:10.1038/nm.3179

19. Mascanfroni ID, Takenaka MC, Yeste A, Patel B, Wu Y, Kenison JE, et al. Metabolic control of type 1 regulatory T cell differentiation by AHR and HIF1-alpha. Nat Med (2015) 21:638-46. doi:10.1038/nm.3868

20. Geem D, Harusato A, Flannigan K, Denning TL. Harnessing regulatory $\mathrm{T}$ cells for the treatment of inflammatory bowel disease. Inflamm Bowel Dis (2015) 21:1409-18. doi:10.1097/MIB.0000000000000343

21. Zhou X, Tang J, Cao H, Fan H, Li B. Tissue resident regulatory T cells: novel therapeutic targets for human disease. Cell Mol Immunol (2015) 12:543-52. doi: $10.1038 / \mathrm{cmi} .2015 .23$

22. Hovhannisyan Z, Treatman J, Littman DR, Mayer L. Characterization of interleukin-17-producing regulatory $\mathrm{T}$ cells in inflamed intestinal mucosa from patients with inflammatory bowel diseases. Gastroenterology (2011) 140:957-65. doi:10.1053/j.gastro.2010.12.002

23. Feuerer M, Herrero L, Cipolletta D, Naaz A, Wong J, Nayer A, et al. Lean, but not obese, fat is enriched for a unique population of regulatory $\mathrm{T}$ cells that affect metabolic parameters. Nat Med (2009) 15:930-9. doi:10.1038/nm.2002

24. Cipolletta D, Feuerer M, Li A, Kamei N, Lee J, Shoelson SE, et al. PPARgamma is a major driver of the accumulation and phenotype of adipose tissue Treg cells. Nature (2012) 486:549-53. doi:10.1038/nature11132

25. Vasanthakumar A, Moro K, Xin A, Liao Y, Gloury R, Kawamoto S, et al. The transcriptional regulators IRF4, BATF and IL-33 orchestrate development and maintenance of adipose tissue-resident regulatory T cells. Nat Immunol (2015) 16:276-85. doi:10.1038/ni.3085

26. Yang S, Fujikado N, Kolodin D, Benoist C, Mathis D. Immune tolerance. regulatory $\mathrm{T}$ cells generated early in life play a distinct role in maintaining self-tolerance. Science (2015) 348:589-94. doi:10.1126/science.aaa7017

27. Atarashi K, Tanoue T, Oshima K, Suda W, Nagano Y, Nishikawa H, et al. Treg induction by a rationally selected mixture of Clostridia strains from the human microbiota. Nature (2013) 500:232-6. doi:10.1038/nature12331

28. Panduro M, Benoist C, Mathis D. Tissue Tregs. Annu Rev Immunol (2016) 34:609-33. doi:10.1146/annurev-immunol-032712-095948

29. Pesenacker AM, Broady R, Levings MK. Control of tissue-localized immune responses by human regulatory T cells. Eur J Immunol (2015) 45:333-43. doi:10.1002/eji.201344205
30. Akimova T, Zhang T, Negorev D, Singhal S, Stadanlick J, Rao A, et al. Human lung tumor FOXP3+ Tregs upregulate four "Treg-locking" transcription factors. JCI Insight (2017) 2(16):e94075. doi:10.1172/jci.insight.94075

31. Svensson H, Olofsson V, Lundin S, Yakkala C, Bjorck S, Borjesson L, et al. Accumulation of CCR4(+)CTLA-4 FOXP3(+)CD25(hi) regulatory T cells in colon adenocarcinomas correlate to reduced activation of conventional T cells. PLoS One (2012) 7:e30695. doi:10.1371/journal.pone.0030695

32. Gyllenhammer LE, Lam J, Alderete TL, Allayee H, Akbari O, Katkhouda N, et al. Lower omental t-regulatory cell count is associated with higher fasting glucose and lower beta-cell function in adults with obesity. Obesity (Silver Spring) (2016) 24:1274-82. doi:10.1002/oby.21507

33. Afzali B, Mitchell PJ, Edozie FC, Povoleri GA, Dowson SE, Demandt L, et al. CD161 expression characterizes a subpopulation of human regulatory $\mathrm{T}$ cells that produces IL-17 in a STAT3-dependent manner. Eur J Immunol (2013) 43:2043-54. doi:10.1002/eji.201243296

34. Donninelli G, Del Corno M, Pierdominici M, Scazzocchio B, Vari R, Varano B, et al. Distinct blood and visceral adipose tissue regulatory $\mathrm{T}$ cell and innate lymphocyte profiles characterize obesity and colorectal cancer. Front Immunol (2017) 8:643. doi:10.3389/fimmu.2017.00643

35. Liu Z, Gerner MY, Van Panhuys N, Levine AG, Rudensky AY, Germain RN. Immune homeostasis enforced by co-localized effector and regulatory T cells. Nature (2015) 528:225-30. doi:10.1038/nature16169

36. Qureshi OS, Zheng Y, Nakamura K, Attridge K, Manzotti C, Schmidt EM, et al. Trans-endocytosis of CD80 and CD86: a molecular basis for the cellextrinsic function of CTLA-4. Science (2011) 332:600-3. doi:10.1126/science. 1202947

37. Fallarino F, Grohmann U, Hwang KW, Orabona C, Vacca C, Bianchi R, et al. Modulation of tryptophan catabolism by regulatory T cells. Nat Immunol (2003) 4:1206-12. doi:10.1038/ni1003

38. Schmidt A, Oberle N, Krammer PH. Molecular mechanisms of Tregmediated T cell suppression. Front Immunol (2012) 3:51. doi:10.3389/ fimmu.2012.00051

39. Ernst PB, Garrison JC, Thompson LF. Much ado about adenosine: adenosine synthesis and function in regulatory $\mathrm{T}$ cell biology. J Immunol (2010) 185:1993-8. doi:10.4049/jimmunol.1000108

40. Grossman WJ, Verbsky JW, Barchet W, Colonna M, Atkinson JP, Ley TJ. Human $\mathrm{T}$ regulatory cells can use the perforin pathway to cause autologous target cell death. Immunity (2004) 21:589-601. doi:10.1016/j.immuni. 2004.09.002

41. Alissafi T, Banos A, Boon L, Sparwasser T, Ghigo A, Wing K, et al. Tregs restrain dendritic cell autophagy to ameliorate autoimmunity. J Clin Invest (2017) 127:2789-804. doi:10.1172/JCI92079

42. Fullerton JN, Gilroy DW. Resolution of inflammation: a new therapeutic frontier. Nat Rev Drug Discov (2016) 15:551-67. doi:10.1038/nrd.2016.39

43. Burzyn D, Kuswanto W, Kolodin D, Shadrach JL, Cerletti M, Jang Y, et al. A special population of regulatory $\mathrm{T}$ cells potentiates muscle repair. Cell (2013) 155:1282-95. doi:10.1016/j.cell.2013.10.054

44. Arpaia N, Green JA, Moltedo B, Arvey A, Hemmers S, Yuan S, et al. A distinct function of regulatory $\mathrm{T}$ cells in tissue protection. Cell (2015) 162:1078-89. doi:10.1016/j.cell.2015.08.021

45. Zaiss DM, van Loosdregt J, Gorlani A, Bekker CP, Grone A, Sibilia M, et al. Amphiregulin enhances regulatory $\mathrm{T}$ cell-suppressive function via the epidermal growth factor receptor. Immunity (2013) 38:275-84. doi:10.1016/j. immuni.2012.09.023

46. Sanchez Rodriguez R, Pauli ML, Neuhaus IM, Yu SS, Arron ST, Harris HW, et al. Memory regulatory $\mathrm{T}$ cells reside in human skin. J Clin Invest (2014) 124:1027-36. doi:10.1172/JCI72932

47. Nosbaum A, Prevel N, Truong HA, Mehta P, Ettinger M, Scharschmidt TC, et al. Cutting edge: regulatory $\mathrm{T}$ cells facilitate cutaneous wound healing. J Immunol (2016) 196:2010-4. doi:10.4049/jimmunol.1502139

48. Ali N, Zirak B, Rodriguez RS, Pauli ML, Truong HA, Lai K, et al. Regulatory $\mathrm{T}$ cells in skin facilitate epithelial stem cell differentiation. Cell (2017) 169:1119-1129e11. doi:10.1016/j.cell.2017.05.002

49. Dombrowski Y, O'Hagan T, Dittmer M, Penalva R, Mayoral SR, Bankhead P, et al. Regulatory $\mathrm{T}$ cells promote myelin regeneration in the central nervous system. Nat Neurosci (2017) 20:674-80. doi:10.1038/nn.4528

50. Lieberman LA, Tsokos GC. The IL-2 defect in systemic lupus erythematosus disease has an expansive effect on host immunity. J Biomed Biotechnol (2010) 2010:740619. doi:10.1155/2010/740619 
51. Koga T, Hedrich CM, Mizui M, Yoshida N, Otomo K, Lieberman LA, et al. CaMK4-dependent activation of AKT/mTOR and CREM-alpha underlies autoimmunity-associated Th17 imbalance. J Clin Invest (2014) 124:2234-45. doi:10.1172/JCI73411

52. Moulton VR, Grammatikos AP, Fitzgerald LM, Tsokos GC. Splicing factor SF2/ASF rescues IL-2 production in T cells from systemic lupus erythematosus patients by activating IL-2 transcription. Proc Natl Acad Sci U S A (2013) 110:1845-50. doi:10.1073/pnas.1214207110

53. Moulton VR, Tsokos GC. T cell signaling abnormalities contribute to aberrant immune cell function and autoimmunity. J Clin Invest (2015) 125:2220-7. doi:10.1172/JCI78087

54. Crispin JC, Tsokos GC. IL-17 in systemic lupus erythematosus. J Biomed Biotechnol (2010) 2010:943254. doi:10.1155/2010/943254

55. Gomez-Martin D, Diaz-Zamudio M, Crispin JC, Alcocer-Varela J. Interleukin 2 and systemic lupus erythematosus: beyond the transcriptional regulatory net abnormalities. Autoimmun Rev (2009) 9:34-9. doi:10.1016/j. autrev.2009.02.035

56. Humrich JY, Morbach H, Undeutsch R, Enghard P, Rosenberger S, Weigert O, et al. Homeostatic imbalance of regulatory and effector $\mathrm{T}$ cells due to IL-2 deprivation amplifies murine lupus. Proc Natl Acad Sci U S A (2010) 107:204-9. doi:10.1073/pnas.0903158107

57. Ohl K, Tenbrock K. Regulatory T cells in systemic lupus erythematosus. Eur J Immunol (2015) 45:344-55. doi:10.1002/eji.201344280

58. Schmidt A, Rieger CC, Venigalla RK, Elias S, Max R, Lorenz HM, et al. Analysis of FOXP3(+) regulatory T cell subpopulations in peripheral blood and tissue of patients with systemic lupus erythematosus. Immunol Res (2017) 65:551-63. doi:10.1007/s12026-017-8904-4

59. Costa N, Marques O, Godinho SI, Carvalho C, Leal B, Figueiredo AM, et al. Two separate effects contribute to regulatory $\mathrm{T}$ cell defect in systemic lupus erythematosus patients and their unaffected relatives. Clin Exp Immunol (2017) 189:318-30. doi:10.1111/cei.12991

60. Gutierrez-Ramos JC, Andreu JL, Revilla Y, Vinuela E, Martinez C. Recovery from autoimmunity of MRL/lpr mice after infection with an interleukin-2/ vaccinia recombinant virus. Nature (1990) 346:271-4. doi:10.1038/ $346271 \mathrm{a} 0$

61. Gutierrez-Ramos JC, Andreu JL, Marcos MA, Vegazo IR, Martinez C. Treatment with IL2/vaccinia recombinant virus leads to serologic, histologic and phenotypic normalization of autoimmune MRL/lpr-lpr mice. Autoimmunity (1991) 10:15-25. doi:10.3109/08916939108997143

62. Huggins ML, Huang FP, Xu D, Lindop G, Stott DI. Modulation of autoimmune disease in the MRL-lpr/lpr mouse by IL-2 and TGF-betal gene therapy using attenuated Salmonella typhimurium as gene carrier. Lupus (1999) 8:29-38. doi:10.1191/096120399678847308

63. Mizui M, Koga T, Lieberman LA, Beltran J, Yoshida N, Johnson MC, et al. IL-2 protects lupus-prone mice from multiple end-organ damage by limiting CD4-CD8- IL-17-producing T cells. J Immunol (2014) 193:2168-77. doi:10.4049/jimmunol.1400977

64. Crispin JC, Oukka M, Bayliss G, Cohen RA, Van Beek CA, Stillman IE, et al. Expanded double negative T cells in patients with systemic lupus erythematosus produce IL-17 and infiltrate the kidneys. J Immunol (2008) 181:8761-6. doi:10.4049/jimmunol.181.12.8761

65. Humrich JY, Riemekasten G. Restoring regulation - IL-2 therapy in systemic lupus erythematosus. Expert Rev Clin Immunol (2016) 12:1153-60. doi:10.1080/1744666X.2016.1199957

66. von Spee-Mayer C, Siegert E, Abdirama D, Rose A, Klaus A, Alexander T, et al. Low-dose interleukin-2 selectively corrects regulatory T cell defects in patients with systemic lupus erythematosus. Ann Rheum Dis (2016) 75:1407-15. doi:10.1136/annrheumdis-2015-207776

67. Koreth J, Ritz J, Tsokos G, Pugliese A, Malek T, Rosenzwajg M, et al. Lowdose interleukin-2 in the treatment of autoimmune disease. Hematol Oncol $\operatorname{Rev}(2014)$ 10:157-63.

68. Hirakawa M, Matos TR, Liu H, Koreth J, Kim HT, Paul NE, et al. Low-dose IL-2 selectively activates subsets of CD4(+) Tregs and NK cells. JCI Insight (2016) 1:e89278. doi:10.1172/jci.insight.89278

69. Zabransky DJ, Nirschl CJ, Durham NM, Park BV, Ceccato CM, Bruno TC, et al. Phenotypic and functional properties of helios+ regulatory $\mathrm{T}$ cells. PLoS One (2012) 7:e34547. doi:10.1371/journal.pone.0034547
70. van der Veeken J, Gonzalez AJ, Cho H, Arvey A, Hemmers S, Leslie CS, et al. Memory of inflammation in regulatory T cells. Cell (2016) 166:977-90. doi:10.1016/j.cell.2016.07.006

71. Churlaud G, Jimenez V, Ruberte J, Amadoudji Zin M, Fourcade G, Gottrand G, et al. Sustained stimulation and expansion of Tregs by IL2 control autoimmunity without impairing immune responses to infection, vaccination and cancer. Clin Immunol (2014) 151:114-26. doi:10.1016/j.clim.2014.02.003

72. Bonnet B, Vigneron J, Levacher B, Vazquez T, Pitoiset F, Brimaud F, et al. Low-dose IL-2 induces regulatory T cell-mediated control of experimental food allergy. J Immunol (2016) 197:188-98. doi:10.4049/jimmunol.1501271

73. Menzel T, Schomburg A, Korfer A, Hadam M, Meffert M, Dallmann I, et al. Clinical and preclinical evaluation of recombinant PEG-IL-2 in human. Cancer Biother (1993) 8:199-212. doi:10.1089/cbr.1993.8.199

74. Wu K, Ma J, Bai W, Cui X, Han T, Wang S, et al. Short-term intratracheal use of PEG-modified IL-2 and glucocorticoid persistently alleviates asthma in a mouse model. Sci Rep (2016) 6:31562. doi:10.1038/srep31562

75. Bell CJ, Sun Y, Nowak UM, Clark J, Howlett S, Pekalski ML, et al. Sustained in vivo signaling by long-lived IL-2 induces prolonged increases of regulatory T cells. J Autoimmun (2015) 56:66-80. doi:10.1016/j.jaut.2014.10.002

76. Yan JJ, Lee JG, Jang JY, Koo TY, Ahn C, Yang J. IL-2/anti-IL-2 complexes ameliorate lupus nephritis by expansion of CD4(+)CD25(+)Foxp3(+) regulatory T cells. Kidney Int (2017) 91:603-15. doi:10.1016/j.kint.2016.09.022

77. Arenas-Ramirez N, Woytschak J, Boyman O. Interleukin-2: biology, design and application. Trends Immunol (2015) 36:763-77. doi:10.1016/j. it.2015.10.003

78. McHugh MD, Park J, Uhrich R, Gao W, Horwitz DA, Fahmy TM. Paracrine co-delivery of TGF-beta and IL-2 using CD4-targeted nanoparticles for induction and maintenance of regulatory $\mathrm{T}$ cells. Biomaterials (2015) 59:172-81. doi:10.1016/j.biomaterials.2015.04.003

79. Gerriets VA, Kishton RJ, Johnson MO, Cohen S, Siska PJ, Nichols AG, et al. Foxp3 and Toll-like receptor signaling balance Treg cell anabolic metabolism for suppression. Nat Immunol (2016) 17:1459-66. doi:10.1038/ni.3577

80. Zeng H, Yang K, Cloer C, Neale G, Vogel P, Chi H. mTORC1 couples immune signals and metabolic programming to establish T(reg)-cell function. Nature (2013) 499:485-90. doi:10.1038/nature12297

81. Procaccini C, De Rosa V, Galgani M, Abanni L, Cali G, Porcellini A, et al. An oscillatory switch in mTOR kinase activity sets regulatory $\mathrm{T}$ cell responsiveness. Immunity (2010) 33:929-41. doi:10.1016/j.immuni.2010.11.024

82. Apostolidis SA, Rodriguez-Rodriguez N, Suarez-Fueyo A, Dioufa N, Ozcan E, Crispin JC, et al. Phosphatase PP2A is requisite for the function of regulatory T cells. Nat Immunol (2016) 17:556-64. doi:10.1038/ni.3390

83. Shrestha S, Yang K, Guy C, Vogel P, Neale G, Chi H. Treg cells require the phosphatase PTEN to restrain TH1 and TFH cell responses. Nat Immunol (2015) 16:178-87. doi:10.1038/ni.3076

84. Huynh A, DuPage M, Priyadharshini B, Sage PT, Quiros J, Borges CM, et al. Control of PI(3) kinase in Treg cells maintains homeostasis and lineage stability. Nat Immunol (2015) 16:188-96. doi:10.1038/ni.3077

85. Qiao G, Zhao Y, Li Z, Tang PQ, Langdon WY, Yang T, et al. T cell activation threshold regulated by E3 ubiquitin ligase Cbl-b determines fate of inducible regulatory T cells. J Immunol (2013) 191:632-9. doi:10.4049/ jimmunol.1202068

86. Strauss L, Czystowska M, Szajnik M, Mandapathil M, Whiteside TL. Differential responses of human regulatory T cells (Treg) and effector T cells to rapamycin. PLoS One (2009) 4:e5994. doi:10.1371/journal.pone.0005994

87. Fernandez DR, Telarico T, Bonilla E, Li Q, Banerjee S, Middleton FA, et al. Activation of mammalian target of rapamycin controls the loss of TCRzeta in lupus $\mathrm{T}$ cells through HRES-1/Rab4-regulated lysosomal degradation. J Immunol (2009) 182:2063-73. doi:10.4049/jimmunol.0803600

88. Kato H, Perl A. Mechanistic target of rapamycin complex 1 expands Th17 and IL-4+ CD4-CD8- double-negative T cells and contracts regulatory T cells in systemic lupus erythematosus. J Immunol (2014) 192:4134-44. doi:10.4049/ jimmunol.1301859

89. Warner LM, Adams LM, Sehgal SN. Rapamycin prolongs survival and arrests pathophysiologic changes in murine systemic lupus erythematosus. Arthritis Rheum (1994) 37:289-97. doi:10.1002/art.1780370219

90. Fernandez D, Bonilla E, Mirza N, Niland B, Perl A. Rapamycin reduces disease activity and normalizes $\mathrm{T}$ cell activation-induced calcium fluxing in patients 
with systemic lupus erythematosus. Arthritis Rheum (2006) 54:2983-8. doi:10.1002/art.22085

91. Oaks Z, Winans T, Caza T, Fernandez D, Liu Y, Landas SK, et al. Mitochondrial dysfunction in the liver and antiphospholipid antibody production precede disease onset and respond to rapamycin in lupus-prone mice. Arthritis Rheumatol (2016) 68:2728-39. doi:10.1002/art.39791

92. Canaud G, Bienaime F, Tabarin F, Bataillon G, Seilhean D, Noel LH, et al. Inhibition of the mTORC pathway in the antiphospholipid syndrome. $N$ Engl J Med (2014) 371:303-12. doi:10.1056/NEJMoa1312890

93. Yin Y, Choi SC, Xu Z, Perry DJ, Seay H, Croker BP, et al. Normalization of CD4+ T cell metabolism reverses lupus. Sci Transl Med (2015) 7:274ra18. doi:10.1126/scitranslmed.aaa0835

94. Juang YT, Wang Y, Solomou EE, Li Y, Mawrin C, Tenbrock K, et al. Systemic lupus erythematosus serum IgG increases CREM binding to the IL-2 promoter and suppresses IL-2 production through CaMKIV. J Clin Invest (2005) 115:996-1005. doi:10.1172/JCI22854

95. Otomo K, Koga T, Mizui M, Yoshida N, Kriegel C, Bickerton S, et al. Cutting edge: nanogel-based delivery of an inhibitor of CaMK4 to CD4+ T cells suppresses experimental autoimmune encephalomyelitis and lupus-like disease in mice. J Immunol (2015) 195:5533-7. doi:10.4049/jimmunol.1501603

96. Trenado A, Sudres M, Tang Q, Maury S, Charlotte F, Gregoire S, et al. Ex vivo-expanded $\mathrm{CD} 4+\mathrm{CD} 25+$ immunoregulatory $\mathrm{T}$ cells prevent graftversus-host-disease by inhibiting activation/differentiation of pathogenic T cells. J Immunol (2006) 176:1266-73. doi:10.4049/jimmunol.176.2.1266

97. Cao T, Soto A, Zhou W, Wang W, Eck S, Walker M, et al. Ex vivo expanded human CD4+CD25+Foxp3+ regulatory $\mathrm{T}$ cells prevent lethal xenogenic graft versus host disease (GVHD). Cell Immunol (2009) 258:65-71. doi:10.1016/j.cellimm.2009.03.013

98. Sagoo P, Ali N, Garg G, Nestle FO, Lechler RI, Lombardi G. Human regulatory $\mathrm{T}$ cells with alloantigen specificity are more potent inhibitors of alloimmune skin graft damage than polyclonal regulatory T cells. Sci Transl Med (2011) 3:83ra42. doi:10.1126/scitranslmed.3002076

99. Romano M, Tung SL, Smyth LA, Lombardi G. Treg therapy in transplantation: a general overview. Transpl Int (2017) 30:745-53. doi:10.1111/tri.12909
100. Scotta C, Fanelli G, Hoong SJ, Romano M, Lamperti EN, Sukthankar M, et al. Impact of immunosuppressive drugs on the therapeutic efficacy of ex vivo expanded human regulatory T cells. Haematologica (2016) 101:91-100. doi:10.3324/haematol.2015.128934

101. Bluestone JA, Buckner JH, Fitch M, Gitelman SE, Gupta S, Hellerstein MK, et al. Type 1 diabetes immunotherapy using polyclonal regulatory $\mathrm{T}$ cells. $\mathrm{Sci}$ Transl Med (2015) 7:315ra189. doi:10.1126/scitranslmed.aad4134

102. Scalapino KJ, Tang Q, Bluestone JA, Bonyhadi ML, Daikh DI. Suppression of disease in New Zealand Black/New Zealand white lupus-prone mice by adoptive transfer of ex vivo expanded regulatory T cells. J Immunol (2006) 177:1451-9. doi:10.4049/jimmunol.177.3.1451

103. Weigert O, von Spee C, Undeutsch R, Kloke L, Humrich JY, Riemekasten G. CD4+Foxp3+ regulatory $\mathrm{T}$ cells prolong drug-induced disease remission in (NZBxNZW) F1 lupus mice. Arthritis Res Ther (2013) 15:R35. doi:10.1186/ ar4188

104. Betts BC, Pidala J, Kim J, Mishra A, Nishihori T, Perez L, et al. IL-2 promotes early Treg reconstitution after allogeneic hematopoietic cell transplantation. Haematologica (2017) 102:948-57. doi:10.3324/haematol.2016.153072

105. Pilon CB, Petillon S, Naserian S, Martin GH, Badoual C, Lang P, et al. Administration of low doses of IL-2 combined to rapamycin promotes allogeneic skin graft survival in mice. Am J Transplant (2014) 14:2874-82. doi:10.1111/ajt.12944

Conflict of Interest Statement: The authors declare that the research was conducted in the absence of any commercial or financial relationships that could be construed as a potential conflict of interest.

Copyright (ङ) 2018 Mizui and Tsokos. This is an open-access article distributed under the terms of the Creative Commons Attribution License (CC BY). The use, distribution or reproduction in other forums is permitted, provided the original author(s) and the copyright owner are credited and that the original publication in this journal is cited, in accordance with accepted academic practice. No use, distribution or reproduction is permitted which does not comply with these terms. 